\title{
Quantifying methane and nitrous oxide emissions from the UK and Ireland using a national-scale monitoring network
}

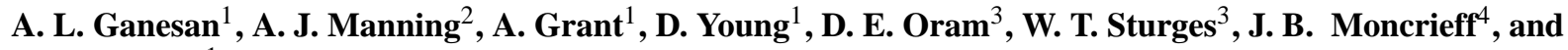 \\ S. O'Doherty ${ }^{1}$ \\ ${ }^{1}$ School of Chemistry, University of Bristol, Bristol, UK \\ ${ }^{2}$ Hadley Centre, Met Office, Exeter, UK \\ ${ }^{3}$ School of Environmental Sciences, University of East Anglia, Norwich Research Park, Norwich, UK \\ ${ }^{4}$ School of Geosciences, University of Edinburgh, Edinburgh, UK
}

Correspondence to: A. L. Ganesan (anita.ganesan@bristol.ac.uk)

Received: 28 October 2014 - Published in Atmos. Chem. Phys. Discuss.: 9 January 2015

Revised: 6 May 2015 - Accepted: 18 May 2015 - Published: 11 June 2015

\begin{abstract}
The UK is one of several countries around the world that has enacted legislation to reduce its greenhouse gas emissions. In this study, we present top-down emissions of methane $\left(\mathrm{CH}_{4}\right)$ and nitrous oxide $\left(\mathrm{N}_{2} \mathrm{O}\right)$ for the UK and Ireland over the period August 2012 to August 2014. These emissions were inferred using measurements from a network of four sites around the two countries. We used a hierarchical Bayesian inverse framework to infer fluxes as well as a set of covariance parameters that describe uncertainties in the system. We inferred average UK total emissions of 2.09 (1.65-2.67) $\mathrm{Tg} \mathrm{yr}^{-1} \mathrm{CH}_{4}$ and $0.101(0.068-0.150) \mathrm{Tg} \mathrm{yr}^{-1}$ $\mathrm{N}_{2} \mathrm{O}$ and found our derived UK estimates to be generally lower than the a priori emissions, which consisted primarily of anthropogenic sources and with a smaller contribution from natural sources. We used sectoral distributions from the UK National Atmospheric Emissions Inventory (NAEI) to determine whether these discrepancies can be attributed to specific source sectors. Because of the distinct distributions of the two dominant $\mathrm{CH}_{4}$ emissions sectors in the UK, agriculture and waste, we found that the inventory may be overestimated in agricultural $\mathrm{CH}_{4}$ emissions. We found that annual mean $\mathrm{N}_{2} \mathrm{O}$ emissions were consistent with both the prior and the anthropogenic inventory but we derived a significant seasonal cycle in emissions. This seasonality is likely due to seasonality in fertilizer application and in environmental drivers such as temperature and rainfall, which are not reflected in the annual resolution inventory. Through the hierarchical Bayesian inverse framework, we quantified uncertainty covariance parameters and emphasized their importance for high-resolution emissions estimation. We in-
\end{abstract}

ferred average model errors of approximately 20 and $0.4 \mathrm{ppb}$ and correlation timescales of $1.0(0.72-1.43)$ and 2.6 (1.93.9) days for $\mathrm{CH}_{4}$ and $\mathrm{N}_{2} \mathrm{O}$, respectively. These errors are a combination of transport model errors as well as errors due to unresolved emissions processes in the inventory. We found the largest $\mathrm{CH}_{4}$ errors at the Tacolneston station in eastern England, which may be due to sporadic emissions from landfills and offshore gas in the North Sea.

\section{Introduction}

Methane $\left(\mathrm{CH}_{4}\right)$ and nitrous oxide $\left(\mathrm{N}_{2} \mathrm{O}\right)$ are the second and third most important long-lived greenhouse gases after carbon dioxide $\left(\mathrm{CO}_{2}\right)$ and have 100-year global warming potentials with climate-carbon feedback of 34 and 298, respectively (Myhre et al., 2013). Because of their importance to climate, there is considerable interest in quantifying emissions at the national level for the purposes of policy and reduction measures.

In 2008, the UK brought into legislation the Climate Change Act 2008 (http://www.legislation.gov.uk/ukpga/ 2008/27/contents) with the legally binding target to reduce the country's $\mathrm{CO}_{2}$ equivalent emissions (by global warming potential) by at least $80 \%$ of 1990 levels by 2050. As part of the efforts over the past several decades to quantify emissions, the UK government produces the National Atmospheric Emissions Inventory (NAEI, http://naei.defra.gov. uk), which currently includes a yearly gridded $1 \mathrm{~km} \times 1 \mathrm{~km}$ sectoral inventory of UK anthropogenic emissions of the ma- 
jor greenhouse gases (Fig. 1). National total emissions from this inventory are submitted yearly to the United Framework Convention on Climate Change (UNFCCC, www.unfccc. int), which requires developed countries to annually report their emissions of $\mathrm{CO}_{2}, \mathrm{CH}_{4}, \mathrm{~N}_{2} \mathrm{O}$, sulfur hexafluoride $\left(\mathrm{SF}_{6}\right)$, hydrofluorocarbons (HFCs) and perfluorocarbons (PFCs). In 2012, the UK reported $2.42 \mathrm{Tg} \mathrm{yr}^{-1} \mathrm{CH}_{4}$ with an uncertainty of $20 \%$ and $0.116 \mathrm{Tg} \mathrm{yr}^{-1} \mathrm{~N}_{2} \mathrm{O}$ with an uncertainty of $69 \%$ in the UNFCCC 2014 UK National Inventory Report. Of all the gases in the UK inventory, $\mathrm{N}_{2} \mathrm{O}$ has the highest emissions uncertainty. In the same year, Ireland reported $0.575 \mathrm{Tg} \mathrm{yr}^{-1}$ $\mathrm{CH}_{4}$ with an uncertainty of $20 \%$ and $0.024 \mathrm{Tg} \mathrm{yr}^{-1} \mathrm{~N}_{2} \mathrm{O}$ with an uncertainty of $88 \%$ in the Ireland National Inventory Report.

Globally, emissions of these gases into the atmosphere come from both biogenic and anthropogenic sources. In the UK however, anthropogenic sources dominate over natural sources (Tables 1 and 2 and references therein). The principal anthropogenic sources of $\mathrm{CH}_{4}$ in the UK in 2012, as reported from NAEI inventories, were from agriculture (44\% of anthropogenic emissions), waste (40\%) and energy (15\%). For $\mathrm{N}_{2} \mathrm{O}$, NAEI reported emissions were largely from agricultural soils $(75 \%)$, followed by fuel combustion $(11 \%)$ and animal waste management $(8 \%)$. Tables 3 and 4 provide the contribution of the major anthropogenic and natural sources to the UK and Ireland inventory totals.

Alongside efforts to maintain a detailed bottom-up inventory, which compiles information using emissions factors and source information, four monitoring stations were implemented around the UK and Ireland to infer emissions through top-down methods using atmospheric observations. Quantification of emissions at the national level requires dense measurement networks to provide enough coverage and information to constrain fluxes at high resolution. The four greenhouse gas stations of the UK DECC (Deriving Emissions linked to Climate Change) network were situated to constrain emissions of potent greenhouse gases from the UK. These four stations are located at Mace Head (MHD, $53.33^{\circ} \mathrm{N}$, $9.90^{\circ} \mathrm{W}, 25 \mathrm{~m}$ a.s.1.) on the western coast of Ireland, and telecommunication towers at Ridge Hill (RGL, $52.00^{\circ} \mathrm{N}$, $2.54^{\circ} \mathrm{W}, 204 \mathrm{~m}$ a.s.1.) in western England, Tacolneston (TAC, $52.52^{\circ} \mathrm{N}, 1.14^{\circ} \mathrm{E}, 56 \mathrm{~m}$ a.s.l.) in eastern England and Angus (TTA, $56.56^{\circ} \mathrm{N}, 2.99^{\circ} \mathrm{W}, 400 \mathrm{~m}$ a.s.1.) in eastern Scotland. While operations at Mace Head have been supported by the UK government for several decades, the latter three sites were funded by the UK's Department of Energy and Climate Change beginning in 2011. With the exception of Angus, which currently only measures $\mathrm{CO}_{2}$ and $\mathrm{CH}_{4}$, the remaining sites are additionally equipped to monitor $\mathrm{N}_{2} \mathrm{O}$ and $\mathrm{SF}_{6}$.

Emissions of $\mathrm{CH}_{4}$ and $\mathrm{N}_{2} \mathrm{O}$ have previously been estimated both globally and regionally for the UK and northwest Europe using inverse methods (Manning et al., 2011; Corazza et al., 2011; Bergamaschi et al., 2015). While global emissions have been estimated to be around $554 \pm 56$ and
$15.7 \pm 1.1 \mathrm{Tg}^{-} \mathrm{N} \mathrm{yr}^{-1}$ (Prather et al., 2012), respectively, regional and national-scale emissions are significantly more uncertain. Manning et al. (2011) used a regional approach to infer emissions for the UK using measurements from Mace Head, Ireland and found the UK's contribution in 2007 to be $1.9(0.8-3.3) \mathrm{Tg} \mathrm{yr}^{-1} \mathrm{CH}_{4}$ and $0.070(0.055-0.090) \mathrm{Tg} \mathrm{yr}^{-1}$ $\mathrm{N}_{2} \mathrm{O}$. Bergamaschi et al. (2015), using a variety of global and regional approaches, derived 2006-2007 emissions for the UK and Ireland that ranged between $2.5-4.8 \mathrm{Tg} \mathrm{yr}^{-1}$ for $\mathrm{CH}_{4}$ and $0.07-0.17 \mathrm{Tg} \mathrm{yr}^{-1}$ for $\mathrm{N}_{2} \mathrm{O}$, depending on the inversion method and chemical transport model (with NAME derived emissions generally being lower than those from the other studies). The large range in derived emissions, which were almost always larger than the individual uncertainties of each model/inversion, highlights the need for robust uncertainty quantification and investigation into systematic model errors.

The objectives of this study were to: (1) quantify UK and Ireland emissions of $\mathrm{CH}_{4}$ and $\mathrm{N}_{2} \mathrm{O}$ using atmospheric observations for the period of August 2012 to August 2014; (2) use spatial patterns in derived emissions to understand sources of discrepancy between the top-down and bottom-up inventories at the sectoral and regional levels; (3) quantify critical uncertainty parameters, including spatially and temporally varying variances and correlations using a hierarchical Bayesian inverse method (Ganesan et al., 2014); (4) use the derived parameters to inform development of nationalscale monitoring networks.

\section{Measurements}

Information about the network stations and measurement setup has been summarized in Table 5. Observations of atmospheric $\mathrm{CH}_{4}$ and $\mathrm{N}_{2} \mathrm{O}$ mole fraction have been collected since 1987 and 1978, respectively, at Mace Head, Ireland, which is one of the core long-term observatories of the Advanced Global Atmospheric Gases Experiment (AGAGE). Ambient air measurements were made on a gas chromatograph (GC, Agilent 5890) equipped with a flame ionization detector (FID, Carle) for $\mathrm{CH}_{4}$ and electron capture detector (ECD, Agilent) for $\mathrm{N}_{2} \mathrm{O}$ every $40 \mathrm{~min}$. Standards were filled wet in electropolished stainless steel cylinders and were calibrated on the Tohoku University and SIO-98 calibration scales, respectively. A detailed description of the methodology can be found in Prinn et al. (2000).

Measurement at the telecommunications towers at Ridge Hill, Tacolneston and Angus have been made since March 2012, July 2012 and March 2011, respectively, with $\mathrm{CH}_{4}$ measurement occurring at all three sites and $\mathrm{N}_{2} \mathrm{O}$ measurement occurring only at Ridge Hill and Tacolneston (http://www.metoffice.gov.uk/atmospheric-trends/). Methane analysis was conducted using a Picarro Cavity Ring Down spectrometer (CRDS). Ridge Hill and Tacolneston were equipped with the G2301 CRDS instrument 

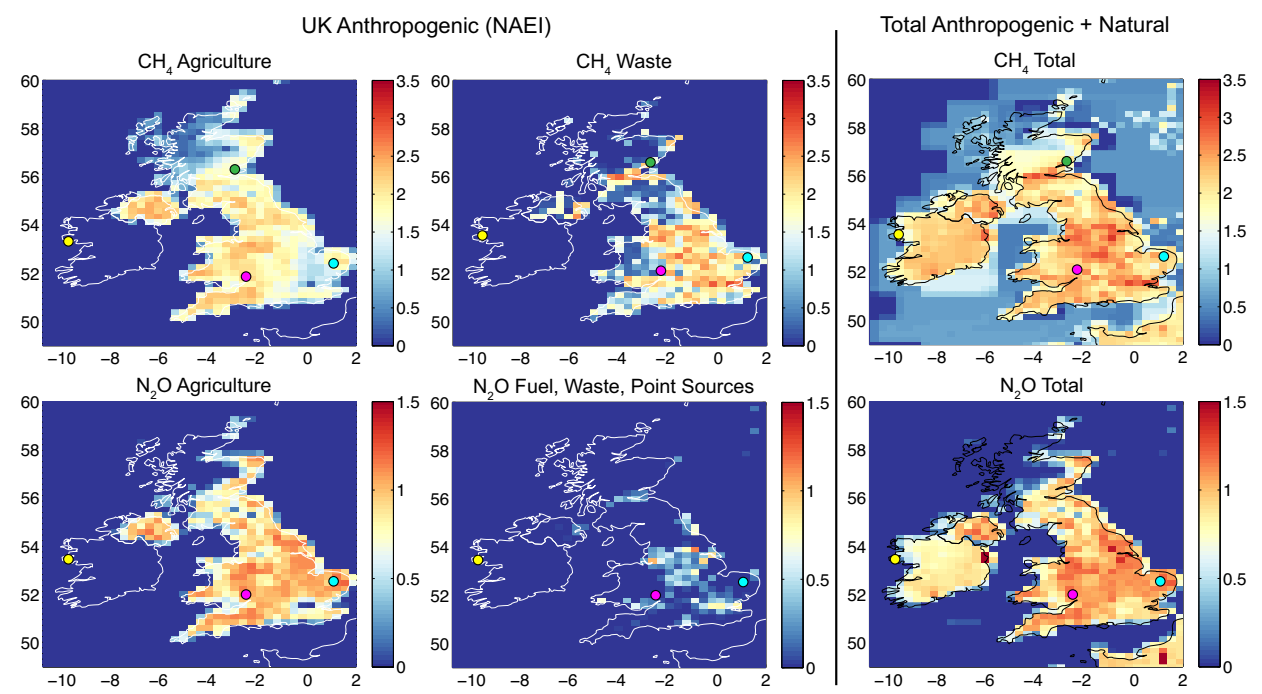

Figure 1. A priori emissions of $\mathrm{CH}_{4}$ and $\mathrm{N}_{2} \mathrm{O}$ in $\log _{10}\left(\mathrm{~g}\right.$ gridcell ${ }^{-1} \mathrm{~s}^{-1}$ ). (Left) Major UK anthropogenic source sectors from the National Atmospheric Emissions Inventory. (Right) Annual average of total a priori emissions, including natural and anthropogenic sources for all countries. Colored circles show the measurement stations (MHD, yellow; RGL, magenta; TAC, cyan; TTA, green.)

Table 1. Sources of a priori emissions used in the $\mathrm{CH}_{4}$ study. Superscript $\mu$ denotes that these are the median values of the distribution.

\begin{tabular}{lll}
\hline Parameter & Category & Prior \\
\hline & Anthropogenic & NAEI or 2008 EDGAR 4.2 scaled to UNFCCC country totals (JRC/PBL, 2011) \\
$\boldsymbol{x}^{\mu}$ & Wetlands and rice & 2008 emissions from Bloom et al. (2012) scaled by percentage of natural soil (Morton et al., 2011; EEA, 2007) \\
& Biomass burning & 2008 emissions from GFED v 3.1 (van der Werf et al., 2010) \\
& Other natural & Fung et al. (1991) \\
& Soil sink & Bousquet et al. (2006) \\
\hline $\boldsymbol{x}^{\mu}$ & Polynomial baseline & Fit to statistically observed baseline at Mace Head over 2012-2013 \\
& Offsets & Median fraction-weighted difference between upper air influenced observations and baseline / zero for horizontal directions \\
\hline$\sigma_{x}^{\mu}$ & Emissions & Lognormal SD corresponding to national scale emissions uncertainty of 50\% \\
\hline$\sigma_{x}^{\mu}$ & Polynomial baseline & Uncertainties from fit calculation \\
\hline$\sigma_{y \mathrm{t}}^{\mu}$ & Offsets & 10 ppb \\
$\sigma_{y \mathrm{~s}}^{\mu}$ & & SD of observations at all sites in each 2 day period \\
\hline$\tau^{\mu}$ & & SD of observations at each site over the month \\
$v^{\mu}$ & & 2 days (typical duration of pollution events) \\
$l^{\mu}$ & & 0.5 (exponential) \\
\hline
\end{tabular}

continuously over the measurement period and employed sample drying using a Nafion membrane driven by a dry countercurrent gas. Angus measurements were made on the G1301 series until May 2013, after which a G2301 model was installed. No sample drying was employed at this site. A water vapor correction (as measured by the instrument) was used at all sites and all measurements were calibrated using dry standards filled in aluminum cylinders. Methane observations were calibrated on the NOAA-2004 calibration scale and were converted to the Tohoku University scale for consistency with Mace Head observations using a calibration factor of 1.0003 (Dlugokencky et al., 2005). Sampling heights on the towers were 45 and $90 \mathrm{ma.g.l}$. at Ridge Hill; 54, 100 and 185 ma.g.l. at Tacolneston and
222 ma.g.l. at Angus. For stations with multiple inlets, each height was sampled sequentially. In this study, an average measurement of the two lowest heights was used (measurements from $185 \mathrm{ma}$.g.l. at Tacolneston were not used due to the additional complexity of representing this height in the boundary layer).

Nitrous oxide observations at the telecommunication tower sites were made approximately every $10 \mathrm{~min}$ on a GCECD system, based on the system described in Ganesan et al. (2013) and Hall et al. (2011) and were calibrated on the SIO98 scale. For the $\mathrm{N}_{2} \mathrm{O}$ configuration, measurements at Ridge Hill and Tacolneston were only made at 90 and 100 ma.g.1., respectively. 
Table 2. Same as Table 1 but for $\mathrm{N}_{2} \mathrm{O}$.

\begin{tabular}{|c|c|c|}
\hline Parameter & Category & Prior \\
\hline$x^{\mu}$ & $\begin{array}{l}\text { Anthropogenic } \\
\text { Natural soils } \\
\text { Biomass burning } \\
\text { Ocean }\end{array}$ & $\begin{array}{l}\text { NAEI or } 2008 \text { EDGAR } 4.2 \text { scaled to UNFCCC country totals (JRC/PBL, 2011) } \\
2008 \text { emissions from Saikawa et al. (2013) scaled by percentage of natural soil (Morton et al., 2011; EEA, 2007) } \\
2008 \text { emissions from GFED v } 3.1 \text { (van der Werf et al., 2010) } \\
\text { Manizza et al. (2012) }\end{array}$ \\
\hline$x^{\mu}$ & $\begin{array}{l}\text { Polynomial baseline } \\
\text { Offsets }\end{array}$ & $\begin{array}{l}\text { Fit to statistically observed baseline at Mace Head over 2012-2013 } \\
\text { Median fraction-weighted difference between upper air influenced observations and baseline/zero for horizontal directions }\end{array}$ \\
\hline$\sigma_{x}^{\mu}$ & Emissions & Lognormal SD corresponding to national scale emissions uncertainty of $100 \%$ \\
\hline$\sigma_{x}^{\mu}$ & $\begin{array}{l}\text { Polynomial baseline } \\
\text { Offsets }\end{array}$ & $\begin{array}{l}\text { Uncertainties from fit calculation } \\
2 \mathrm{ppb}\end{array}$ \\
\hline $\begin{array}{l}\sigma_{y \mathbf{t}}{ }^{\mu} \\
\sigma_{y \mathbf{s}}\end{array}$ & & $\begin{array}{l}\text { SD of observations at all sites in each } 2 \text { day period } \\
\text { SD of observations at each site over the month }\end{array}$ \\
\hline $\begin{array}{l}\tau \\
v \\
l\end{array}$ & & $\begin{array}{l}2 \text { days (typical duration of pollution events) } \\
0.5 \text { (exponential function) } \\
250 \mathrm{~km} \text { (smallest distance between the four measurement sites) }\end{array}$ \\
\hline
\end{tabular}

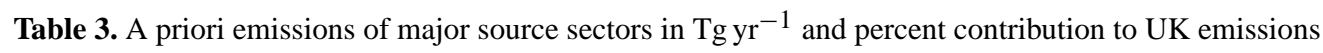

\begin{tabular}{llll}
\hline Species & Prior & $\begin{array}{l}\text { January emissions } \\
(\% \text { of total })\end{array}$ & $\begin{array}{l}\text { July emissions } \\
(\% \text { of total })\end{array}$ \\
\hline \multirow{2}{*}{$\mathrm{CH}_{4}$} & Anthropogenic, agriculture & $1.06(40)$ & $1.06(39)$ \\
& Anthropogenic, waste & $0.97(36)$ & $0.97(35)$ \\
& Anthropogenic, energy & $0.29(11)$ & $0.29(11)$ \\
& Wetlands and rice & $0.19(7)$ & $0.26(9)$ \\
& Other & $0.17(6)$ & $0.17(6)$ \\
\hline \multirow{2}{*}{$\mathrm{N}_{2} \mathrm{O}$} & Anthropogenic, agriculture & $0.087(72)$ & $0.087(68)$ \\
& Anthropogenic, fuel combustion & $0.013(11)$ & $0.013(11)$ \\
& Anthropogenic, animal waste management & $0.009(8)$ & $0.009(7)$ \\
& Natural soils & $0.006(5)$ & $0.013(10)$ \\
& Other & $0.005(4)$ & $0.005(4)$ \\
\hline
\end{tabular}

Measurements were averaged over $2 \mathrm{~h}$, both day and night. This period was chosen to minimize data volume and to be consistent with the sampling period of the halocarbon measurement system in the network. Data were filtered for local influence using a transport model. Measurements corresponding to times when there was a high sensitivity of mole fractions to emissions from the nine grid cells surrounding the station (at $25 \mathrm{~km}$ resolution) were identified as being likely to be affected by local processes due to the more stagnant air. Local processes act on scales that are smaller than the spatial and temporal resolutions of the model and therefore would not be captured by the model. Furthermore, local processes tend to have a high impact on observations and would therefore lead to large errors in retrieved fluxes. For these reasons, measurements considered to be prone to local effects were removed from the analysis. Approximately 17 (16), 14 (16) , 8 (8) and $4 \%$ of data was filtered from MHD, RGL, TAC and TTA for $\mathrm{CH}_{4}\left(\mathrm{~N}_{2} \mathrm{O}\right)$, respectively.

For $\mathrm{CH}_{4}$ observations, the measurement uncertainty was described by the variability of $1 \mathrm{~min}$ data in the $2 \mathrm{~h}$ averaging period. For $\mathrm{N}_{2} \mathrm{O}$ observations, measurement uncertainty was the sum in quadrature of the instrument precision (calculated as the standard deviation, SD, of the approximately hourly measurements of the standard each day) and the variability in the averaging period. Typical measurement uncertainties

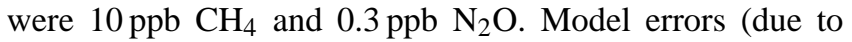
transport errors as well as errors due to unresolved processes) were estimated as part of the inversion framework.

\section{Atmospheric transport model}

The UK Met Office model, NAME III (Numerical Atmospheric dispersion Modelling Environment version 3, henceforth called NAME) was used to quantify the relationship between surface emissions and simulated measurements at each observation point and time. For each $2 \mathrm{~h}$ period, NAME tracked particles backwards in time for 30 days and as particles were transported through the three-dimensional model, recorded the mass of particles and amount of time spent interacting with the first hundred m.a.g.l. (i.e., the surface). This 
Table 4. A priori emissions of major source sectors in $\mathrm{Tg}^{-1}$ and percent contribution to Ireland emissions.

\begin{tabular}{llll}
\hline Species & Prior & $\begin{array}{l}\text { \% of Ireland } \\
\text { emissions (January) }\end{array}$ & $\begin{array}{l}\text { \% of Ireland } \\
\text { emissions (July) }\end{array}$ \\
\hline \multirow{6}{*}{$\mathrm{CH}_{4}$} & Anthropogenic, agriculture & $0.45(70)$ & $0.45(68)$ \\
& Anthropogenic, fugitive emissions & $0.07(11)$ & $0.07(10)$ \\
& Anthropogenic, waste & $0.05(7)$ & $0.05(7)$ \\
& Wetlands and rice & $0.05(8)$ & $0.08(12)$ \\
& Other & $0.03(4)$ & $0.02(3)$ \\
\hline \multirow{2}{*}{$\mathrm{N}_{2} \mathrm{O}$} & Anthropogenic, agriculture & $0.020(80)$ & $0.020(75)$ \\
& Anthropogenic, chemical production & $0.002(6)$ & $0.002(6)$ \\
& Natural soils & $0.001(5)$ & $0.003(10)$ \\
& Other & $0.002(9)$ & $0.002(9)$ \\
\hline
\end{tabular}

Table 5. Ancillary measurement information for the data used this study.

\begin{tabular}{lllllll}
\hline Site & $\begin{array}{l}\text { Lat, Lon, Height } \\
(\mathrm{m} . \text { a.s.1 })\end{array}$ & Species & Instrument & $\begin{array}{l}\text { Calibration } \\
\text { scale }\end{array}$ & $\begin{array}{l}\text { Sampling heights } \\
\text { (m.a.g.l) }\end{array}$ & $\begin{array}{l}\text { Measurement } \\
\text { availability }\end{array}$ \\
\hline MHD & $53.33^{\circ} \mathrm{N}, 9.90^{\circ} \mathrm{W}, 25$ & $\begin{array}{l}\mathrm{CH}_{4} \\
\mathrm{~N}_{2} \mathrm{O}\end{array}$ & $\begin{array}{l}\text { GC-FID } \\
\text { GC-ECD }\end{array}$ & $\begin{array}{l}\text { Tohoku University } \\
\text { SIO-98 }\end{array}$ & $\begin{array}{l}\text { Jan 1987-Aug 2014 } \\
\text { Jul 1978-Aug 2014 }\end{array}$ & $\begin{array}{l}\text { NOAA-2004 } \\
\text { SIO-98 }\end{array}$ \\
\hline \multirow{2}{*}{ RGL } & $52.00^{\circ} \mathrm{N}, 2.54^{\circ} \mathrm{W}, 204$ & $\begin{array}{l}\mathrm{CH}_{4} \\
\mathrm{~N}_{2} \mathrm{O}\end{array}$ & $\begin{array}{l}\text { Picarro G2301 CRDS } \\
\text { GC-ECD }\end{array}$ & $\begin{array}{l}\text { N5, 90 } \\
90\end{array}$ & Mar 2012-Aug 2014 \\
\hline \multirow{2}{*}{ TAC } & $52.52^{\circ} \mathrm{N}, 1.14^{\circ} \mathrm{E}, 56$ & $\begin{array}{l}\mathrm{CH}_{4} \\
\mathrm{~N}_{2} \mathrm{O}\end{array}$ & $\begin{array}{l}\text { Picarro G2301 CRDS } \\
\text { GC-ECD }\end{array}$ & $\begin{array}{l}\text { NOAA-2004 } \\
\text { SIO-98 }\end{array}$ & $\begin{array}{l}54,100 \\
100\end{array}$ & Jul 2012-Aug 2014 \\
\hline \multirow{2}{*}{ TTA } & $56.56^{\circ} \mathrm{N}, 2.99^{\circ} \mathrm{W}, 400$ & $\mathrm{CH}_{4}$ & $\begin{array}{l}\text { Picarro G1301 CRDS } \\
\text { Picarro G2301 CRDS }\end{array}$ & $\begin{array}{l}\text { NOAA-2004 } \\
\text { NOAA-2004 }\end{array}$ & 220 & $\begin{array}{l}\text { Mar 2011-Jan 2013 } \\
\text { May 2013-Aug 2014 }\end{array}$ \\
\hline
\end{tabular}

directly provided the sensitivity of concentrations at the measurement site to surface emissions. Twenty thousand particles were released each hour at a source strength of $1 \mathrm{~g} \mathrm{~s}^{-1}$. The model was driven by the Met Office's Unified Model (UM) analysis meteorology at $0.352^{\circ} \times 0.234^{\circ}$ resolution ( $\sim 25 \mathrm{~km}$ ) with 70 vertical levels. After July 2014, the resolution of the UM meteorology was increased to $\sim 17 \mathrm{~km}$ but NAME output retained the original $\sim 25 \mathrm{~km}$ resolution. The inversion domain extended from approximately 36 to $67^{\circ} \mathrm{N}$ and -14 to $31^{\circ} \mathrm{E}$, covering the UK and most of continental Europe. For the purposes of estimating boundary conditions (discussed further in Sect. 4) a second, larger domain ( 9 to $81^{\circ} \mathrm{N}$ and -100 to $46^{\circ} \mathrm{E}$ at resolution $0.563 \times 0.375^{\circ}$ ) was used to identify the origins of air masses that entered the smaller inversion domain.

A complete description of NAME can be found in Ryall and Maryon (1998), Morrison and Webster (2005) and Jones et al. (2007) and of its use in trace gas emissions estimation in Manning et al. (2011).

\section{Inversion framework}

We followed the hierarchical Bayesian inversion methodology outlined in Ganesan et al. (2014) and extended this method to solve for additional hyper-parameters. This method allows for the systematic estimation of fluxes and critical uncertainty parameters, which was shown to result in a more complete characterization of uncertainties in the system.

For each month of this study, we estimated fluxes from a set of $k$ regions over Europe (with 64 out of 135 regions for $\mathrm{CH}_{4}$ and 51 out of 116 regions for $\mathrm{N}_{2} \mathrm{O}$ occurring over the UK and Ireland) and parameters governing the boundary conditions to the domain. The sizes of the estimated regions were based on the model-derived sensitivities for the measurement sites available for each gas (i.e., Scotland is more highly resolved for $\mathrm{CH}_{4}$ than for $\mathrm{N}_{2} \mathrm{O}$ owing to the additional measurement information at Angus). These unknown parameters comprised vector $\boldsymbol{x}$. Sensitivities of mole fractions to emissions from these regions were a priori emissions weighted average of the sensitivities from individual grid cells and so the distribution of the prior within each region was retained in the inversion.

\subsection{Hyper-parameters}

We estimated the mean and standard deviation, $\boldsymbol{\mu}_{x}$ and $\boldsymbol{\sigma}_{x}$, respectively, which described the emissions PDF and a set of hyper-parameters that characterized the model-measurement 
likelihood. These were $\sigma_{y \mathrm{t}}$ and $\boldsymbol{\sigma}_{y \mathrm{~s}}$, which described temporal and spatial variances of a separable covariance matrix (described further below) and correlation parameters, $\tau, v$ and $l$. These variances described the mismatch between modeled and observed mole fractions and include the effects of model error and any errors due to unresolved processes. The correlation timescale, $\tau$, described an exponentially decaying temporal correlation and the spatial correlation length-scale, $l$, and smoothness parameter, $v$, described a Matérn covariance function (Stein, 1999).

$\mathbf{T}$ and $\mathbf{S}$ are the separable time and space components of covariance $\mathbf{R}$ (described further in Sect. 4.3), where $\sigma_{y t}$ contains the variances of $\mathbf{T}$ and $\tau$ forms the off-diagonals and $\boldsymbol{\sigma}_{y \mathrm{~s}}$ contains the variances of $\mathbf{S}$ and $v, l$ form the offdiagonals. $\sigma_{y \mathrm{t}}$ was estimated for each 2 day period of the month and $\sigma_{y \mathrm{~s}}$ was derived for each site over the month. Temporal correlation was represented by Eq. (1) with $t_{i j}$ representing each element in covariance matrix, $\mathbf{T}$ for points $i$ and $j$ separated by time $t$. The Matérn covariance function is a commonly used function in spatial statistics to describe covariance between two points, $i$ and $j$ separated by Euclidean distance, $d$. It is described by Eq. (2), with $s_{i j}$ representing the elements in spatial covariance matrix, $\mathbf{S}$. $\Gamma$ is the gamma function and $K_{\nu}$ is the modified Bessel function of the second kind. When $v=0.5$, the Matern function becomes an exponential covariance function and when $v \gg 0.5$, it approaches a squared exponential function (similar to Gaussian).

$t_{i j}=\sqrt{t_{i i}} \cdot \sqrt{t_{j j}} \cdot \exp \left(\frac{-t}{\tau}\right)$

$s_{i j}=\sqrt{s_{i i}} \cdot \sqrt{s_{j j}} \cdot \frac{1}{\Gamma(v) 2^{v-1}}\left(\sqrt{2 v} \frac{d}{l}\right)^{v} K_{v}\left(\sqrt{2 v} \frac{d}{l}\right)$.

Solving for these hyper-parameters allows us to account for "uncertainties in uncertainties" and reduce the effect of subjective assumptions on a priori emissions uncertainties, model uncertainties and correlation scales. Fluxes, boundary conditions and hyper-parameters were informed by the data, $z$, through a Markov chain Monte Carlo (MCMC) framework, which has previously been shown to result in a more complete uncertainty quantification because these parameters and their uncertainties are passed systematically through the inversion (Ganesan et al., 2014; Rigby et al., 2011).

\subsection{Boundary conditions}

Boundary conditions were estimated for each of ten boundaries to the domain and represented the part of the measured concentration not simulated by the 30 day air histories. A schematic for these boundaries is provided in Fig. 2. Multiple boundary conditions were estimated to represent the variable levels and directions from which air enters the domain (for example, due to a north-south gradient). The boundary conditions represent the concentrations on the boundaries of the outer domain, which is thought to be the direction associated with the "source" of the air mass (e.g., winds that

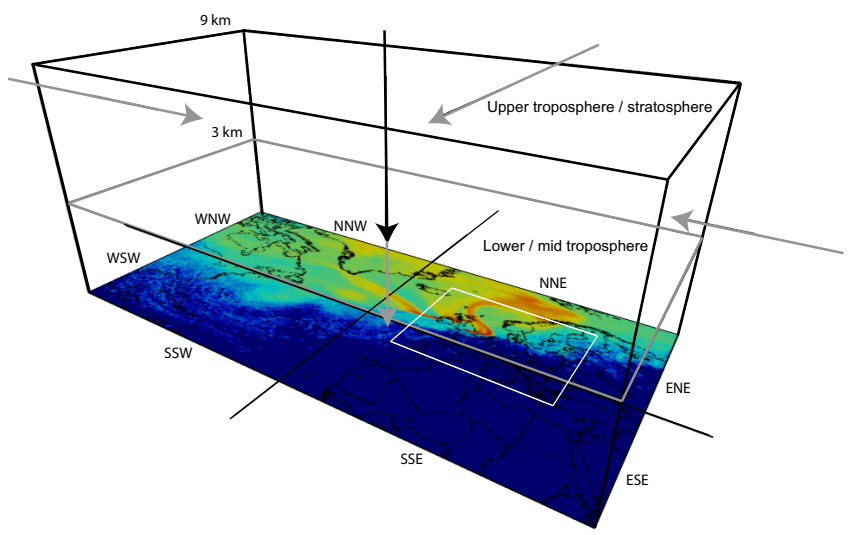

Figure 2. Schematic of boundary conditions (BCs) estimated as part of the inversion. The inversion domain is represented by the inner white box. The map shows combined air histories for all four sites at a given instance and illustrates that the stations can sample different "baselines" at the same time due to differences in their meteorology. PDF parameters to $17 \mathrm{BCs}$ were estimated in total; eight defining the polynomial that governs the WSW boundary and offsets for seven other horizontal boundaries and two upper atmosphere boundaries (arrows in grey correspond to the BC governing air entering the 3-9 $\mathrm{km}$ box and the arrow in black corresponds to the BC governing air from above $9 \mathrm{~km}$ ).

enter the inner inversion domain from the west sometimes originate from the southern outer boundary). Therefore, the concentrations entering the inner inversion domain are comprised of the concentrations on the outer boundaries plus the effect of any emissions in between the two domains. For some directions (in particular the northeast), there could be significant emissions sources, however, from the predominant directions (southwest and northwest), emissions sources are expected to be smaller. These emission sources do not significantly affect the fluxes derived in the inversion, which require boundary conditions to simulate the net concentrations outside of the inversion domain; however, physical interpretation of the boundary conditions must account for these emissions.

The boundary condition to the west-south-west (WSW) edge was formulated as a polynomial shown by Eq. (3), with six sinusoidal terms, a linear trend term and an offset term, for time $t$ over total period $T$.

$$
\begin{aligned}
\mathrm{BC}_{\mathrm{WSW}}= & \sum_{i}^{3}\left[a_{i} \cdot \sin \left(\frac{2 \pi i\left(t-t_{0}\right)}{T}\right)+b_{i} \cdot \cos \left(\frac{2 \pi i\left(t-t_{0}\right)}{T}\right)\right] \\
& +c t+d .
\end{aligned}
$$

Offsets to this WSW boundary represented the values on the seven other horizontal boundaries, a boundary from 3 to $9 \mathrm{~km}$ (low to mid troposphere) and a boundary at $9 \mathrm{~km}$ (upper troposphere to stratosphere). In total, PDF parameters to 17 boundary conditions were estimated as part of the inversion each month. Sensitivities to these boundary conditions were computed for each site by using the model to track which 
direction and height air had entered the domain over the previous 30 days for each $2 \mathrm{~h}$ simulation. It was assumed that each baseline parameter remained constant over the month and was the same for all sites, though the effect of air coming from each boundary would be "felt" at different times, depending on the meteorology of that particular site. A full description of the boundary condition estimation method is provided in the Supplement.

\subsection{Estimation scheme}

The hierarchical estimation scheme can be outlined as follows:

$\boldsymbol{y}=\mathbf{H} \boldsymbol{x}+\boldsymbol{\epsilon}$

$\boldsymbol{\epsilon} \sim N(\mathbf{0}, \mathbf{R})$

$z=\mathbf{C} \boldsymbol{y}+\boldsymbol{\eta}$

$\boldsymbol{\eta} \sim N(\mathbf{0}, \mathbf{D})$,

where $\boldsymbol{y}$ is a vector of model simulated mole fractions of size $m n$ for all times during the period of interest and for all sites (including times/locations when no observations exist), $\mathbf{H}$ is a $m n \times k$ array of model sensitivities that maps $\boldsymbol{x}$ to $\boldsymbol{y}$ and $\boldsymbol{\epsilon}$ is a stochastic error term. $\mathbf{C}$ is a $p \times m n$ matrix that samples values of $\boldsymbol{y}$ at the $p$ times/locations that observations exist, $z$ is a vector of $p$ observations with stochastic error $\boldsymbol{\eta}$ and $\mathbf{D}$ is a $p \times p$ "nugget" term of uncorrelated instrumental uncertainties. The covariance matrix, $\mathbf{R}$, governs the model uncertainty for all possible observations in time and space. For example, if measurements were made every $2 \mathrm{~h}$ over a year at four sites, there would be $4380(365 \times 12)$ possible measurements at four locations and $\mathbf{T}$ would be of size 4380 and $\mathbf{S}$ of size four. It is likely, however, that some of these measurements would be missing due to instrumental or site problems and $\boldsymbol{y}$ is an additional parameter that is sampled in the MCMC chain and compared to observations through matrix $\mathbf{C}$. Therefore, we assume that errors in the model will be correlated even at times/locations that observations do not exist.

The joint distribution of $\boldsymbol{x}, \boldsymbol{\mu}_{\boldsymbol{x}}, \boldsymbol{\sigma}_{\boldsymbol{x}}, \boldsymbol{\sigma}_{y \mathrm{t}}, \boldsymbol{\sigma}_{y \mathrm{~s}}, \tau, \nu, l$ and $\boldsymbol{y}$ is expressed through Eq. (8), through the hierarchical propagation of Bayes' theorem and the probability chain rule, where $\rho(\cdot)$ describes the prior PDF and $\rho(\cdot \mid \cdot)$ is a conditional of the first parameter given the second.

$$
\begin{aligned}
& \rho\left(\boldsymbol{x}, \boldsymbol{\mu}_{\boldsymbol{x}}, \boldsymbol{\sigma}_{x}, \boldsymbol{\sigma}_{y \mathrm{t}}, \boldsymbol{\sigma}_{y \mathrm{~s}}, \tau, v, l, \boldsymbol{y} \mid \boldsymbol{z}\right) \propto \rho(\boldsymbol{z} \mid \boldsymbol{y}, \mathbf{D}) \\
& \cdot \rho\left(\boldsymbol{y} \mid \boldsymbol{x}, \boldsymbol{\sigma}_{y \mathrm{t}}, \boldsymbol{\sigma}_{y \mathrm{~s}}, \tau, v, l\right) \\
& \cdot \rho\left(\boldsymbol{x} \mid \boldsymbol{\mu}_{\boldsymbol{x}}, \boldsymbol{\sigma}_{\boldsymbol{x}}\right) \\
& \cdot \rho\left(\boldsymbol{\mu}_{\boldsymbol{x}}\right) \cdot \rho\left(\boldsymbol{\sigma}_{\boldsymbol{x}}\right) \cdot \rho\left(\boldsymbol{\sigma}_{y \mathrm{t}}\right) \cdot \rho\left(\boldsymbol{\sigma}_{y \mathrm{~s}}\right) \cdot \rho(\tau) \cdot \rho(v) \cdot \rho(l) .
\end{aligned}
$$

As shown in Eq. (8), each hyper-parameter $\left(\boldsymbol{\mu}_{x}, \boldsymbol{\sigma}_{x}, \boldsymbol{\sigma}_{y \mathrm{t}}\right.$, $\left.\sigma_{y s}, \tau, \nu, l\right)$ requires an a priori PDF to be specified. Through MCMC, these PDFs are sampled from and used to form the posterior PDF. The lognormal distribution ( $\mathrm{LN}$ ) was used for $\boldsymbol{x}, \boldsymbol{\mu}_{x}, \boldsymbol{\sigma}_{x}, \boldsymbol{\sigma}_{y}$ and $\boldsymbol{\sigma}_{y \mathrm{~s}}$ to represent skewed distributions that are not defined for negative values. This prevents unphysical solutions from being reached. A discrete uniform distribution $(U)$ was used as a non-informative prior for correlation hyper-parameters, $\tau, v$ and $l$. Model and measurement uncertainties were assumed to be Gaussian $(N)$ as it was assumed that these random errors were symmetric around the median. Regions that contained a net sink (for $\mathrm{N}_{2} \mathrm{O}$, some oceanic areas are sinks at certain times of the year) were estimated with Gaussian distributions.

By assimilating data from multiple sites and at highfrequency, the size of the estimation problem can get very large for MCMC. To reduce the computational cost of multiplying, inverting and computing the determinant of large matrices over 50000 iterations, it was assumed that the covariance matrix, $\mathbf{R}$, was separable in space and time (Eq. 9). This has been widely employed in geostatistics, where it is assumed that correlations in time are not dependent on position and correlations in space are not dependent on time (e.g., Meirink et al., 2008; Thompson et al., 2011; Yadav and Michalak, 2013).

$\mathbf{R}\left(t, t+\Delta_{t}, s, s+\Delta_{\mathrm{s}}\right)=\mathbf{T}\left(t, t+\Delta_{t}\right) \mathbf{S}\left(s, s+\Delta_{\mathrm{s}}\right)$.

By assuming separability in the covariance matrix, we could exploit the following properties:

1. $\mathbf{R}=\mathbf{T} \otimes \mathbf{S}$, where separable square matrix $\mathbf{R}$ of size $m n$ can be written as the Kronecker product of two matrices governing the temporal and spatial covariances, respectively. $\mathbf{T}$ is a square matrix of size $m$ and $\mathbf{S}$ is a square matrix of size $n$.

2. $\mathbf{R}^{-1}=(\mathbf{T} \otimes \mathbf{S})^{-1}=\mathbf{T}^{-1} \otimes \mathbf{S}^{-1}$, so the computation of the inverse of a square matrix of size $m n$ can be decomposed into the inverse of two smaller matrices.

3. $\operatorname{det}(\mathbf{R})=\operatorname{det}(\mathbf{T} \otimes \mathbf{S})=\operatorname{det}(\mathbf{T})^{n} \operatorname{det}(\mathbf{S})^{m}$, so the computation of the determinant of a square matrix of size $m n$ can be decomposed into the determinant of two smaller similar matrices.

4. $\boldsymbol{a}=\mathbf{R}^{-1} \boldsymbol{b}$, where $\boldsymbol{a}$ and $\boldsymbol{b}$ are vectors of length $m n$. In this analysis, $\boldsymbol{b}$ represents residual vector $(\boldsymbol{y}-\mathbf{H} \boldsymbol{x})$ and $\boldsymbol{a}$ represents the vector required to compute the likelihoods in Eq. (8). This operation can now be computed as $\mathbf{A}=\mathbf{S}^{-1} \mathbf{B} \mathbf{T}^{-1^{T}}$, where $\mathbf{B}$ is an array composed of $\boldsymbol{b}$ reordered to size $n \times m$ and $\mathbf{A}$, also of dimension $n \times m$ can be restacked to form $\boldsymbol{a}$. The advantage of this computation is that the Kronecker product forming $\mathbf{R}$ does not need to be explicitly computed and the product of the (large) covariance matrix and vector can be reformulated as the product of smaller arrays. 
Because the computational cost of these operations are approximately of the order $n^{3}$, assuming separability makes a dramatic improvement in efficiency for MCMC.

\subsection{A priori values}

Tables 1 and 2 describe the a priori median values for all of the hyper-parameters of the system (with the superscript $\mu$ referring to the median of that respective distribution). Hyper-parameter SDs of the lognormal distributions (denoted by superscript $\sigma), \boldsymbol{\mu}_{\boldsymbol{x}}^{\sigma}, \boldsymbol{\sigma}_{x}^{\sigma}, \boldsymbol{\sigma}_{y \mathrm{t}}^{\sigma}$ and $\boldsymbol{\sigma}_{y \mathrm{~s}}^{\sigma}$ were calculated such that the 16th to 84th (cf., $1 \sigma$ of a Gaussian distribution) percentile range was equal to $100 \%$ of the median emissions.

Gridded anthropogenic emissions for the UK were from the NAEI for 2012. Anthropogenic emissions for other countries were taken from the Emission Database for Global Atmospheric Research version 4.2 (EDGAR, JRC/PBL, 2011) but these emissions were scaled by country to the UNFCCC reported emissions to maintain consistency with the numbers reported by individual countries.

Natural emissions were compiled from a variety of sources outlined in Tables 1 and 2. To account for anthropogenic land that was classed as natural in these inventories (for example, the natural soil $\mathrm{N}_{2} \mathrm{O}$ source did not mask out agricultural land), natural emissions were scaled by the fraction of natural land in each UK and European country based on land cover maps (Morton et al., 2011; EEA, 2007). While there are additional complexities with classifying emissions from land as natural or anthropogenic, we assume that this scaling approach will, to first-order, correct for overestimation in natural inventories. The contributions of the major source sectors to the UK and Ireland totals are presented in Tables 3 and 4 . Anthropogenic sources were approximately $90 \%$ of the total for both gases.

A priori, it was assumed that offsets to the horizontal boundary conditions was zero (i.e., the MHD baseline was assumed for all horizontal directions). For upper-air boundary conditions, the mean fraction-weighted (based on sensitivities derived by the NAME model) difference between upper-air influenced observations and baseline was assumed.

\section{Results and discussion}

We present top-down $\mathrm{CH}_{4}$ and $\mathrm{N}_{2} \mathrm{O}$ emissions for the UK and Ireland from August 2012 to August 2014 along with an analysis of the uncertainty parameters derived in the inversion. Results are presented as the median of the posterior PDFs and uncertainties for all parameters correspond to the 5 th to 95 th percentile range. In addition, the simulated posterior and prior time series, derived baselines and comparison with observations are provided in the Supplement.
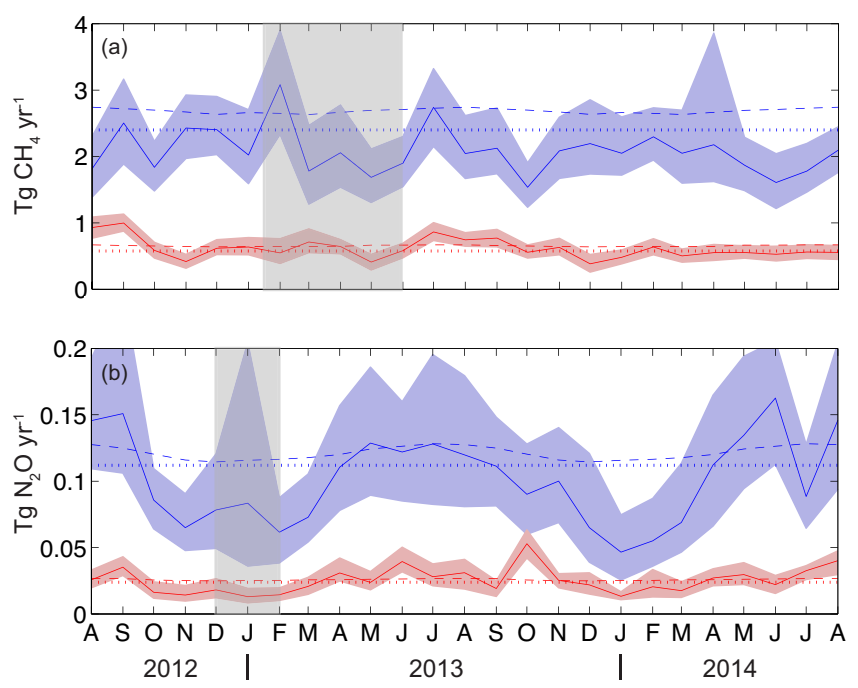

Figure 3. Median posterior (a) $\mathrm{CH}_{4}$ and (b) $\mathrm{N}_{2} \mathrm{O}$ emissions in $\mathrm{Tg} \mathrm{yr}^{-1}$ for the UK (blue) and Ireland (red). Solid lines correspond to top-down estimates, dashed lines to the total prior emissions and dotted lines to the anthropogenic component of the prior. Shading on emissions corresponds to the 5th to 95th percentile range of the posterior distribution. The grey shading corresponds to times where data from a station were largely missing (TTA for $\mathrm{CH}_{4}$ and RGL for $\mathrm{N}_{2} \mathrm{O}$ ).

\subsection{Emissions and boundary conditions}

Figure 3 shows $\mathrm{CH}_{4}$ and $\mathrm{N}_{2} \mathrm{O}$ emissions by month over the study period. On average, the UK's emissions were 2.09 (1.65-2.67) $\mathrm{Tg} \mathrm{yr}^{-1} \mathrm{CH}_{4}$ and 0.101 (0.068-0.150) $\mathrm{Tg} \mathrm{yr}^{-1} \mathrm{~N}_{2} \mathrm{O}$ and Ireland's emissions were $0.62(0.50-0.74) \mathrm{Tg} \mathrm{yr}^{-1} \mathrm{CH}_{4}$ and $0.025 \quad(0.019$ $0.033) \mathrm{Tg} \mathrm{yr}^{-1} \mathrm{~N}_{2} \mathrm{O}$. Both UK $\mathrm{CH}_{4}$ and $\mathrm{N}_{2} \mathrm{O}$ emissions were generally lower than the total and anthropogenic a priori emissions. The difference in annual average $\mathrm{CH}_{4}$ emissions from the total prior is statistically significant (with the annual average prior lying outside of the uncertainty of the posterior) but the $\mathrm{N}_{2} \mathrm{O}$ difference is not significant when accounting for uncertainties. A change in natural emissions, which are only $5-12 \%$ of the prior for both gases, may explain some of the difference, but is likely not large enough to account for all of it. Emissions from Ireland were consistent with the prior for both gases.

The $\mathrm{CH}_{4}$ emissions derived in this study are statistically consistent with the 2007 UK emissions estimated by Manning et al. (2011), while the $\mathrm{N}_{2} \mathrm{O}$ emissions are slightly higher. The uncertainties derived in this study are smaller for $\mathrm{CH}_{4}$ but larger for $\mathrm{N}_{2} \mathrm{O}$ and the differences in uncertainties for the two studies are likely due to the different methodologies used as well as the additional measurement stations in this study. The hierarchical method provides a framework for more completely and rigorously characterizing random uncertainties in the system, but does not account for system- 

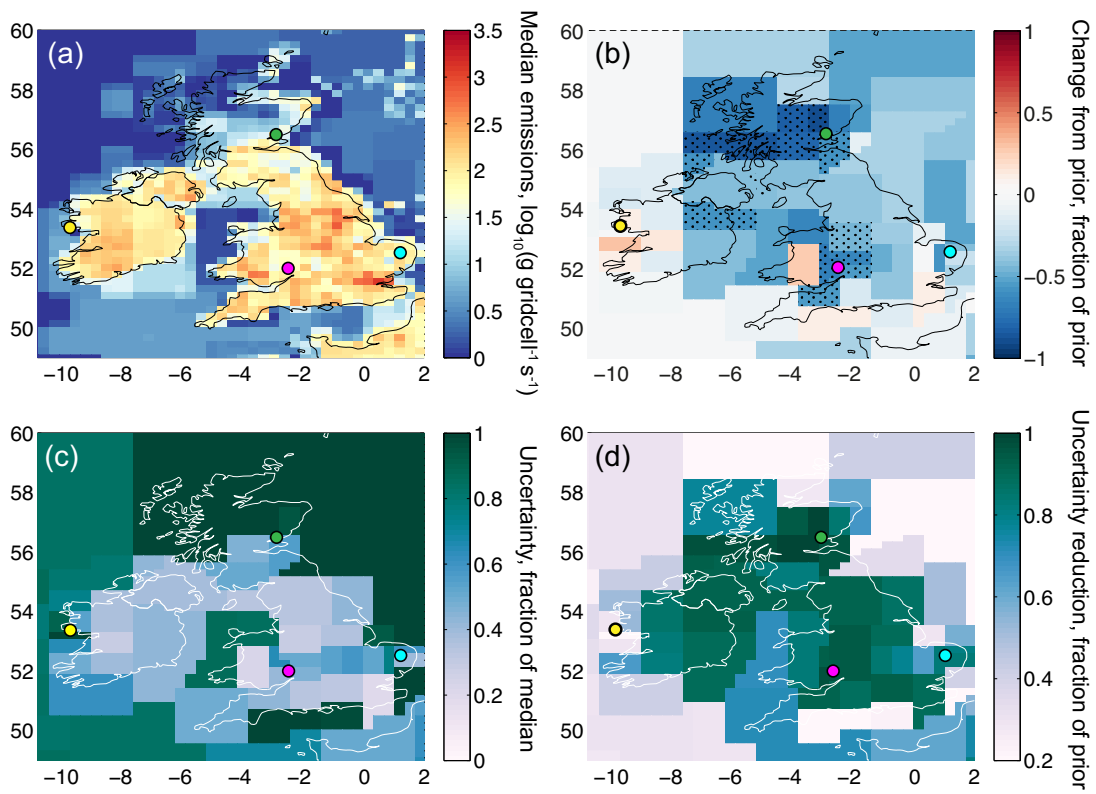

Figure 4. (a) Median posterior $\mathrm{CH}_{4}$ emissions shown on a logarithmic scale. Emissions have been disaggregated from the larger regions estimated in the inversion using the prior distribution. (b) Difference between the median posterior emissions and the prior, relative to the prior. Dots show statistically significant differences, where the prior emissions lie outside of the 5th to 95th percentile range of the posterior emissions. (c) Posterior emissions uncertainty. This corresponds to the average difference between the median and the 5th and 95th percentiles, relative to the median. (d) Uncertainty reduction from the prior, relative to the prior. Colored circles show the measurement stations (MHD, yellow; RGL, magenta; TAC, cyan; TTA, green).

atic uncertainties. The emissions and uncertainties derived here lie in the lower range of results obtained by Bergamaschi et al. (2015), and while they could be attributed to the additional measurement stations used, they likely also point to large systematic differences between models.

Methane emissions between February and May 2013 were the most uncertain due to missing data from Angus and similarly, $\mathrm{N}_{2} \mathrm{O}$ emissions in December 2012 and January 2013 had larger uncertainties than other times of the year due to the fact that the $\mathrm{N}_{2} \mathrm{O}$ instrumentation at Ridge Hill was down during those two months. Uncertainties were on average approximately $36 \%$ larger on $\mathrm{UK} \mathrm{CH}_{4}$ emissions during January-May 2013 and $50 \%$ larger on UK $\mathrm{N}_{2} \mathrm{O}$ emissions during December 2013-January 2014, than the average of months sampled by the full network.

Boundary conditions from the WSW, WNW, NNW, NNE and the two upper air directions were the most constrained, as reflected by the significant uncertainty reduction from the prior (over $50 \%$ ), while air from the other directions were almost never sampled and thus reflected the prior distributions.

While $\mathrm{CH}_{4}$ emissions do not show significant seasonality, $\mathrm{N}_{2} \mathrm{O}$ in contrast has a pronounced seasonal cycle, with a maximum in the summer months and minimum in the winter. Though the a priori emissions have a small seasonal cycle due to the natural soil and oceanic sources of $\mathrm{N}_{2} \mathrm{O}$, the derived amplitude of approximately $0.05 \mathrm{Tg} \mathrm{yr}^{-1}$ is much larger in the posterior estimates and is statistically signif- icant. Thompson et al. (2014) found a seasonal cycle over Europe with a timing consistent with our findings, however the magnitude of the seasonal cycle was larger and matched closely with the prior that was used. The difference in amplitude is likely to do with the greater prevalence of natural soils in Europe as a whole rather than in the UK. A small seasonality was found in Ireland's $\mathrm{N}_{2} \mathrm{O}$ emissions but this seasonality was not significant relative to the uncertainties.

Figures 4 and 5 show spatial maps of median derived emissions for the two gases over the study period, the percentage difference from the prior, fractional uncertainties (ratio of the difference between 5th and 95th percentiles to the median) and uncertainty reduction from the prior. Dots in the difference map indicate regions where the difference was statistically significant (i.e., the prior was outside the 5th to 95th percentile range of the posterior emissions).

Spatial maps of the dominant sectors of the UK NAEI are shown in Fig. 1. Comparison of the posterior emissions distribution with the sectoral inventory maps allows us to determine whether differences between the top-down and bottomup emissions can be attributed to particular sectors. The two dominant and approximately equivalent sources of $\mathrm{CH}_{4}$ in the UK are agriculture (cattle, manure) and waste (landfill) sectors, each contributing approximately 40 and $35 \%$ of the total prior emissions respectively. While agricultural sources are more diffuse than landfill sources, the maps for the waste sector show a distinct spatial pattern. The waste 

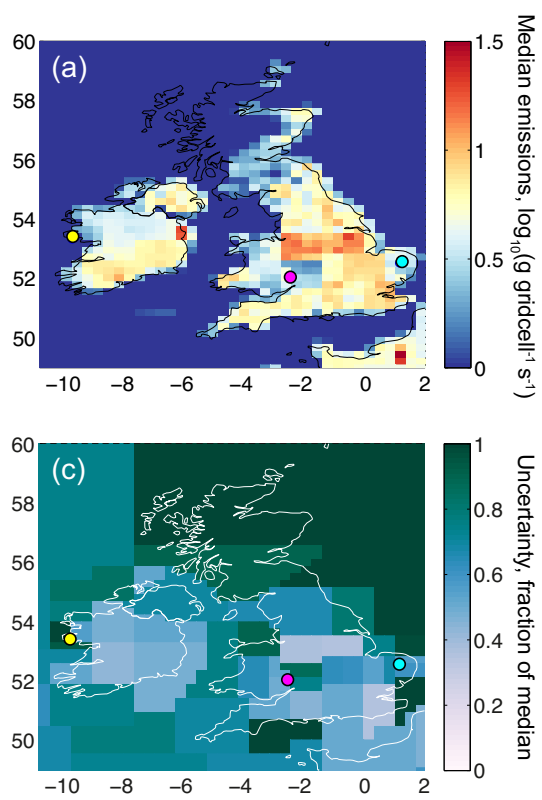

Figure 5. Same as Fig. 4 but for $\mathrm{N}_{2} \mathrm{O}$.

sector dominates emissions from eastern and central England. Agricultural emissions are generally well-distributed around the country with the highest emissions in western England, Wales, Northern Ireland and southern Scotland, in grassland regions where livestock production is prevalent. While emissions from the entire domain are generally lower than the prior, the largest difference, as a percentage of the prior, occurs throughout Scotland, western England and eastern Ireland. An analysis of the uncertainties derived for each region for each month shows these differences to be statistically significant, with the prior lying outside the 5th to 95th percentile range of the posterior distribution. These results suggest that the agricultural sector, due to its prevalence in those regions, may be overestimated in the inventory. The small natural component, which is less than $10 \%$ of the total prior, could also be overestimated, but this would not entirely explain the difference between the prior and the posterior emissions.

In our seasonal analysis for $\mathrm{N}_{2} \mathrm{O}$ (Fig. 6), we find a significant difference between the prior and posterior in winter (December-February), which in part is because there is no seasonal cycle represented in the anthropogenic component of the prior. In the winter, this difference is statistically significant throughout most of the land regions of the UK and Ireland. The NAEI sectoral distribution for agricultural $\mathrm{N}_{2} \mathrm{O}$ shows that emissions are relatively evenly spread around the country, with emissions generally being from fertilized grasslands in the west of England and from fertilized arable land, pig and poultry production in the east. While emissions throughout the UK and Ireland grow toward spring and summer, spatial maps of the posterior emissions show the largest emissions in eastern England during the spring and
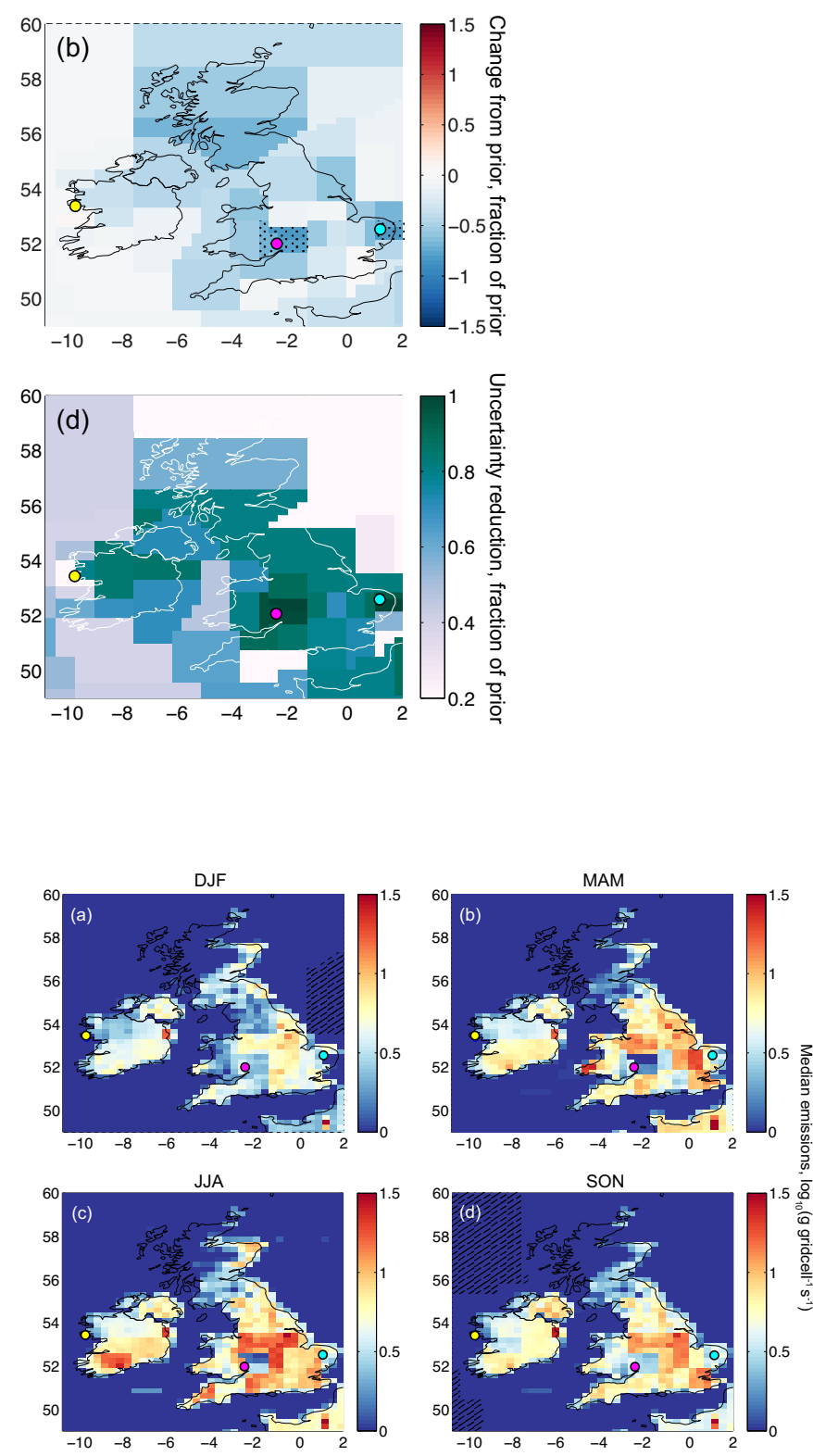

Figure 6. $\mathrm{N}_{2} \mathrm{O}$ emissions by season, shown on a logarithmic scale. Emissions have been disaggregated from the larger regions estimated in the inversion using the prior distribution. Regions with hashing correspond to sink regions and are plotted as their absolute value. Colored circles show the measurement stations (MHD, yellow; RGL, magenta; TAC, cyan).

in central England during the summer. A study over one UK sheep-grazed grassland, which was fertilized three times over the spring and summer, showed fertilizer $\mathrm{N}_{2} \mathrm{O}$ emissions to last from 1 to 3 weeks, following fertilizer application, with the maximum emission occurring in July (Skiba et al., 2012). However, emissions depend strongly not only on fertilizer application, but also on precipitation and temperature and these can have strong regional differences as well as year-to- 
year variability. These findings suggest that the pronounced seasonal cycle is likely to due seasonality in fertilized soils as well as seasonality in environmental drivers, which are not reflected in the annual resolution NAEI inventory. Further elucidating the drivers of this seasonality requires process or empirical models of $\mathrm{N}_{2} \mathrm{O}$ production.

Analysis of the uncertainties derived in the inversion (panels $\mathrm{c}$ and d of Figs. 4 and 5) shows the greatest observational constraint in the $\sim 100 \mathrm{~km}$ around the stations, which predominantly constrain southern and central England and western Ireland. Uncertainties for $\mathrm{N}_{2} \mathrm{O}$ emissions are typically larger than for $\mathrm{CH}_{4}$ emissions, likely due to the lower signalto-noise ratio of $\mathrm{N}_{2} \mathrm{O}$ observations (i.e., $\mathrm{CH}_{4}$ is measured with higher precision and pollution events are larger). For $\mathrm{CH}_{4}$, an increase in emissions was found to occur in Wales. While the difference from the prior was not statistically significant (i.e., the fractional difference from the prior each month typically lay within the 5 to 95 percentiles), the posterior uncertainty showed that the region is well-constrained by the network (and primarily by Ridge Hill). For this region covering eastern Wales, there was considerable monthto-month variability (about half of the months during the period showed this increase and half did not). This is likely caused by poorly resolved meteorology around two large point sources (Cardiff and Swansea) that are surrounded by mountains just to the west of Ridge Hill. This feature could be improved with a more highly resolved grid and/or meteorology in that region.

Two sensitivity studies are provided in the Supplement to assess the effect of the prior on the posterior solution. The first inversion assumed that the prior consisted only of anthropogenic emissions and the second assumed that the natural emissions were not scaled by land-use statistics (an upperbound on natural emissions). We found that the majority of the UK and Ireland were largely insensitive to the choice of prior and that the four station network has enough data density to constrain the UK and Ireland totals. While northern Scotland is not very sensitive in the network, by design this is an area with low emissions and therefore does not significantly impact the UK total.

\subsection{Covariance hyper-parameters}

Figure 7 shows derived model-measurement uncertainties for each site. These uncertainties could be due to model error or any unresolved processes in the inversion. The median posterior value is shown, with error bars indicating the 5th and 95th percentile solutions. On average, uncertainties for the $\mathrm{CH}_{4}$ and $\mathrm{N}_{2} \mathrm{O}$ studies were $\sim 20 \mathrm{ppb}$ and $0.4 \mathrm{ppb}$, respectively. For the $\mathrm{CH}_{4}$ study, Tacolneston consistently exhibited the largest error, the cause of which could be from two factors: the largest $\mathrm{CH}_{4}$ pollution events are measured at Tacolneston and there are known nearby sources (gas fields in the North Sea and landfills in east England) with sporadic emissions that may not be reflected in the temporally
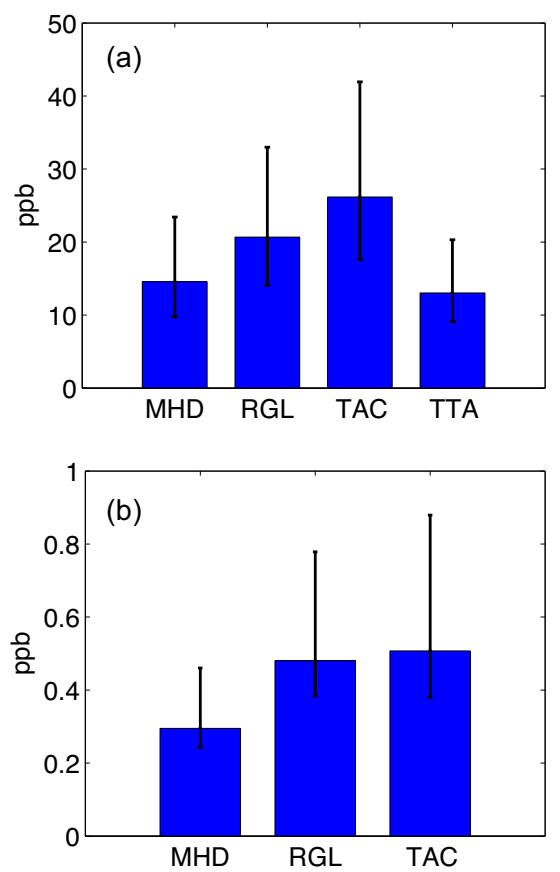

Figure 7. Median (a) $\mathrm{CH}_{4}$ and (b) $\mathrm{N}_{2} \mathrm{O}$ model uncertainties derived for each site. Errorbars show the 5 th to 95 th percentile range.

constant NAEI prior or resolved in the monthly inversion. Mace Head and Angus have the smallest uncertainties, both due to the smaller magnitude of pollution at these sites and due to the more constant regional emissions sources. The increased uncertainty at Tacolneston is reflected in the emissions uncertainties shown in panel c of Fig. 4; uncertainties in the regions surrounding Tacolneston are greater than in the regions surrounding other stations. This feature also highlights that the uncertainties in the various components of the inversion are passed systematically through the inversion to emissions and emission uncertainties. Uncertainties derived for $\mathrm{N}_{2} \mathrm{O}$ are similar for both Tacolneston and Ridge Hill, likely due to both sites generally measuring agricultural emissions, and further suggests that the increased $\mathrm{CH}_{4}$ error at Tacolneston is due to unresolved emissions processes rather than model error at that site. NAME has previously been validated against tracer release experiments, surface and balloon measurements but parametric and structural uncertainties are not well known (Morrison and Webster, 2005; Ryall and Maryon, 1998). Further, validation exercises have not been conducted over the period of this study. While the results of this study cannot discern specific sources of error in the model, this is a subject of great interest and future work.

Spatial and temporal correlation scales were also derived for the two gases. The correlation scales are related to a number of factors: errors in the model transport (e.g., a misplaced weather front at one time will likely be misplaced a short time later) as well as unresolved emissions processes (e.g., errors in the assumption of constant emissions). The two 
sources of correlated errors cannot be disentangled but the time and length scales derived in the inversion are a measure of the scales of the missing or erroneous processes. Average correlation scales of $1.0(0.72-1.43)$ days and 133 (15$317) \mathrm{km}$ were derived over the period for the $\mathrm{CH}_{4}$ study and $2.6(1.9-3.9)$ days and $228(25-450) \mathrm{km}$ for the $\mathrm{N}_{2} \mathrm{O}$ study. The scales are more tightly constrained for $\mathrm{CH}_{4}$ than for $\mathrm{N}_{2} \mathrm{O}$, likely due to the higher signal-to-noise of the observations. The spatial correlation scale is not well-constrained for $\mathrm{N}_{2} \mathrm{O}$ and reflects the prior distribution, indicating that there is not enough information in the network to constrain this parameter. The correlation timescale is smaller for $\mathrm{CH}_{4}$ than for $\mathrm{N}_{2} \mathrm{O}$. Though there are differences in the two networks (i.e., $\mathrm{N}_{2} \mathrm{O}$ is not measured at Angus), a $\mathrm{CH}_{4}$ inversion in which Angus was excluded was also performed and similar correlation scales were derived (Supplement), suggesting that the network differences are not the source of differences in correlation scales. Furthermore, because the same transport model was used for the two studies, model errors were expected to be similar for the two gases so the differences are likely due to unresolved emissions in the prior. We noted the increased variances at Tacolneston and speculated that this was due to sporadic emissions from landfills and offshore gas that were not modeled by the constant prior emissions field and not resolved in the inversion. The longer timescale for $\mathrm{N}_{2} \mathrm{O}$ suggests that unresolved emission characteristics from fertilizers acts on a slightly longer timescale (several days). The correlation length scale of $133 \mathrm{~km}$ for $\mathrm{CH}_{4}$ suggests that the current network, with the nearest two stations being $\sim 250 \mathrm{~km}$ apart, could benefit from additional stations to further constrain $\mathrm{CH}_{4}$ emissions. Given the typical correlation scales that were derived along with knowledge of source distributions, a network can be intelligently designed (or improved) to maximize source information, as we have shown in this study. As measurement networks around the world grow and as countries move toward using top-down methods to infer high resolution emissions, the accurate simulation of covariance parameters will become critical for realistically representing concentrations in the atmosphere and the underlying processes driving them.

\section{Conclusions}

We present an estimate of the UK and Ireland's $\mathrm{CH}_{4}$ and $\mathrm{N}_{2} \mathrm{O}$ emissions from 2012-2014 using a network of four high-frequency and high-precision monitoring stations. We inferred average $\mathrm{CH}_{4}$ emissions of $2.09(1.65-2.67) \mathrm{Tg} \mathrm{yr}^{-1}$ and $\mathrm{N}_{2} \mathrm{O}$ emissions of $0.101(0.068-0.150) \mathrm{Tg} \mathrm{yr}^{-1}$ from the UK and $0.62(0.50-0.74) \mathrm{Tg} \mathrm{yr}^{-1} \mathrm{CH}_{4}$ and 0.025 (0.019$0.033) \mathrm{Tg} \mathrm{yr}^{-1} \mathrm{~N}_{2} \mathrm{O}$ from Ireland over the 2 years of this study. Our top-down results were used to highlight areas where the bottom-up inventory might be improved. We found that the prior (largely from anthropogenic sources) was higher than our estimates of $\mathrm{CH}_{4}$ emissions and likely overestimated from the agriculture sector. The small natural sources in the UK are not likely large enough to account for the full discrepancy between the prior and posterior emissions. Our designation of natural sources is based on land cover statistics but there are additional considerations to be made when classifying land as natural or anthropogenic (e.g., anthropogenic $\mathrm{N}$ deposition on natural land), which were not accounted for here. Average posterior $\mathrm{N}_{2} \mathrm{O}$ emissions were consistent with the prior and the anthropogenic inventory but an enhanced seasonal cycle was found and likely due to seasonality in fertilizer application and in environmental drivers, which are not reflected in the annual resolution anthropogenic inventories.

One limitation of this study is that source processes could only be identified based on differences in spatial distribution. For regions without this separation, such as Ireland, additional measurements would be necessary for source apportionment. The inclusion of $\mathrm{CH}_{4}$ isotopologue measurements at these sites could provide an additional constraint into the gas, landfill and agricultural source partitioning, as has been shown in Rigby et al. (2012).

This study highlights the benefits of using a network for estimating emissions at high-resolution and discusses the considerations that need to be made when using data from these types of networks. Through this study we show the importance of appropriately quantifying uncertainty and covariance parameters. With growing demand for top-down verification of emissions at the country-level, methods need to be employed that account for these important parameters. Through this hierarchical inversion framework, we inferred model errors and uncertainty correlation scales and propagated these uncertainties into the emissions estimates. Model errors for the two studies were on average approximately 20 and $0.4 \mathrm{ppb}$, respectively, but showed variations from site to site and for different times depending on the meteorology. We derived the largest $\mathrm{CH}_{4}$ model errors at Tacolneston, likely due to its proximity to gas extraction in the North Sea and landfills in east England, sources which have sporadic emissions characteristics that are not simulated. We inferred temporal and spatial correlation scales of $1.0(0.72-$ 1.43) days and $133(15-317) \mathrm{km}$ for the $\mathrm{CH}_{4}$ network and $2.6(1.9-3.9)$ days and $228(25-450) \mathrm{km}$ for the $\mathrm{N}_{2} \mathrm{O}$ network, with differences in the two studies likely being due to differences in unresolved emissions processes.

\section{The Supplement related to this article is available online at doi:10.5194/acp-15-6393-2015-supplement.}


Acknowledgements. This modeling study was funded by the UK Department of Energy and Climate Change (DECC) grant GA0201 to the University of Bristol. Operations at Mace Head, Ridge Hill, Tacolneston and Angus were funded by DECC grant GA0201 and partly by the InGOS EU project (284274). Additionally, measurements at Mace Head were also partially funded from NASA grant NNX11AF17G to the Massachusetts Institute of Technology, which supports the Advanced Global Atmospheric Gases Experiment (AGAGE) and at Tacolneston through the NERC National Centre for Atmospheric Research. Calibration of Mace Head data was made possible by NASA grant NNX11AF15G to the Scripps Institution of Technology. The UK National Atmospheric Emissions Inventory (NAEI) was funded by DECC, the Department for Environment, Food and Rural Affairs (Defra), the Scottish Government, the Welsh Government and the Northern Ireland Department of Environment. We are grateful to the station technicians, Gerard Spain (Mace Head), Stephen Humphrey (Tacolneston), Emanuel Blei (Angus, 2013-present) and Rab Howard (Angus, 2012-2013) for maintaining site and instrumental operations and to Matt Rigby for productive discussions on the inverse modeling.

Edited by: F. Fierli

\section{References}

Bergamaschi, P., Corazza, M., Karstens, U., Athanassiadou, M., Thompson, R. L., Pison, I., Manning, A. J., Bousquet, P., Segers, A., Vermeulen, A. T., Janssens-Maenhout, G., Schmidt, M., Ramonet, M., Meinhardt, F., Aalto, T., Haszpra, L., Moncrieff, J., Popa, M. E., Lowry, D., Steinbacher, M., Jordan, A., O’Doherty, S., Piacentino, S., and Dlugokencky, E.: Top-down estimates of European $\mathrm{CH}_{4}$ and $\mathrm{N}_{2} \mathrm{O}$ emissions based on four different inverse models, Atmos. Chem. Phys., 15, 715-736, doi:10.5194/acp-15-715-2015, 2015.

Bloom, A. A., Palmer, P. I., Fraser, A., and Reay, D. S.: Seasonal variability of tropical wetland $\mathrm{CH}_{4}$ emissions: the role of the methanogen-available carbon pool, Biogeosciences, 9, 28212830, doi:10.5194/bg-9-2821-2012, 2012.

Bousquet, P., Ciais, P., Miller, J., Dlugokencky, E., Hauglustaine, D., Prigent, C., Van der Werf, G., Peylin, P., Brunke, E., Carouge, C., Langenfelds, R. L., Lathière, J., Papa, F., Ramonet, M., Schmidt, M., Steele, L. P., Tyler, S., and White, J.: Contribution of anthropogenic and natural sources to atmospheric methane variability, Nature, 443, 439-443, 2006.

Corazza, M., Bergamaschi, P., Vermeulen, A. T., Aalto, T., Haszpra, L., Meinhardt, F., O’Doherty, S., Thompson, R., Moncrieff, J., Popa, E., Steinbacher, M., Jordan, A., Dlugokencky, E., Brühl, C., Krol, M., and Dentener, F.: Inverse modelling of European $\mathrm{N}_{2} \mathrm{O}$ emissions: assimilating observations from different networks, Atmos. Chem. Phys., 11, 2381-2398, doi:10.5194/acp-11-2381-2011, 2011.

Dlugokencky, E. J., Myers, R. C., Lang, P. M., Masarie, K. A., Crotwell, A. M., Thoning, K. W., Hall, B. D., Elkins, J. W., and Steele, L. P.: Conversion of NOAA atmospheric dry air $\mathrm{CH}_{4}$ mole fractions to a gravimetrically prepared standard scale, J. Geophys. Res., 110, D18306, doi:10.1029/2005JD006035, 2005.

European Environment Agency.: Corine Land Cover 2006 technical guidelines. EEA Technical report No 17/2007, www.eea.europa. eu/publications/technical_report_2007_17, last access: 6 March 2015.

Fung, I., John, J., Lerner, J., Matthews, E., Prather, M., Steele, L. P., and Fraser, P. J.: Three-dimensional model synthesis of the global methane cycle, J. Geophys. Res., 96, 13033-13065, doi:10.1029/91JD01247, 1991.

Ganesan, A. L., Chatterjee, A., Prinn, R. G., Harth, C. M., Salameh, P. K., Manning, A. J., Hall, B. D., Mühle, J., Meredith, L. K., Weiss, R. F., O'Doherty, S., and Young, D.: The variability of methane, nitrous oxide and sulfur hexafluoride in Northeast India, Atmos. Chem. Phys., 13, 10633-10644, doi:10.5194/acp-13-10633-2013, 2013.

Ganesan, A. L., Rigby, M., Zammit-Mangion, A., Manning, A. J., Prinn, R. G., Fraser, P. J., Harth, C. M., Kim, K.-R., Krummel, P. B., Li, S., Mühle, J., O’Doherty, S. J., Park, S., Salameh, P. K., Steele, L. P., and Weiss, R. F.: Characterization of uncertainties in atmospheric trace gas inversions using hierarchical Bayesian methods, Atmos. Chem. Phys., 14, 3855-3864, doi:10.5194/acp-14-3855-2014, 2014.

Hall, B. D., Dutton, G. S., Mondeel, D. J., Nance, J. D., Rigby, M., Butler, J. H., Moore, F. L., Hurst, D. F., and Elkins, J. W.: Improving measurements of $\mathrm{SF}_{6}$ for the study of atmospheric transport and emissions, Atmos. Meas. Tech., 4, 2441-2451, doi:10.5194/amt-4-2441-2011, 2011.

Jones, A., Thomson, D. J., Hort, M. C., and Devenish, B.: The UK Met Office's next-generation atmospheric dispersion model, NAME III, in: Air Pollution Modeling and Its Application XVII, edited by: Borrego, C. and Norman, A.-L., Springer, New York, USA, 580-589, 2007.

JRC/PBL: Joint Research Centre of the European Commission (JRC) /Netherlands Environmental Assessment Agency (PBL), Emission Database for Global Atmospheric Research (EDGAR), release version 4.2, available at: http://edgar.jrc.ec.europa.eu (last access: 12 May 2014), 2011.

Manizza, M., Keeling, R. F., and Nevison, C. D.: On the processes controlling the seasonal cycles of the air-sea fluxes of $\mathrm{O}_{2}$ and $\mathrm{N}_{2} \mathrm{O}$ : a modelling study, Tellus B, 64, 18429, doi:10.3402/tellusb.v64i0.18429, 2012.

Manning, A. J., O’Doherty, S., Jones, A. R., Simmonds, P. G., and Derwent, R. G.: Estimating UK methane and nitrous oxide emissions from 1990 to 2007 using an inversion modeling approach, J. Geophys. Res., 116, D02305, doi:10.1029/2010JD014763, 2011.

Meirink, J. F., Bergamaschi, P., and Krol, M. C.: Fourdimensional variational data assimilation for inverse modelling of atmospheric methane emissions: method and comparison with synthesis inversion, Atmos. Chem. Phys., 8, 6341-6353, doi:10.5194/acp-8-6341-2008, 2008.

Morrison, N. L. and Webster, H. N.: An assessment of turbulence profiles in rural and urban environments using local measurements and numerical weather prediction results, Bound.Lay. Meteorol., 115, 223-239, doi:10.1007/s10546-004-4422-8, 2005.

Morton, D., Rowland, C., Wood, C. Meek, L., Marston, C., Smith, G., Wadsworth, R. and Simpson, I. C.: Final Report for LCM2007 - the new UK land cover map, Countryside Survey Technical Report No 11/07 NERC/Centre for Ecology \& Hydrology, 112 pp., (CEH Project Number: C03259), 2011. 
Myhre, G., Shindell, D., Bréon, F.-M., Collins, W., Fuglestvedt, J., Huang, J., Koch, D., Lamarque, J.-F., Lee, D., Mendoza, B., Nakajima, T., Robock, A., Stephens, G., Takemura, T., and Zhang, H.: Anthropogenic and natural radiative forcing, in: Climate Change 2013: The Physical Science Basis. Contribution of Working Group I to the Fifth Assessment Report of the Intergovernmental Panel on Climate Change, edited by: Stocker, T. F., Qin, D., Plattner, G.-K., Tignor, M., Allen, S. K., Boschung, J., Nauels, A., Xia, Y., Bex, V., and Midgley, P. M., Cambridge University Press, Cambridge, United Kingdom and New York, NY, USA, 659-740, 2013.

Prather, M. J., Holmes, C. D., and Hsu, J.: Reactive greenhouse gas scenarios: systematic exploration of uncertainties and the role of atmospheric chemistry, Geophys. Res. Lett., 39, L09803, doi:10.1029/2012GL051440, 2012.

Prinn, R. G., Weiss, R. F., Fraser, P. J., Simmonds, P. G., Cunnold, D. M., Alyea, F. N., O'Doherty, S., Salameh, P., Miller, B. R., Huang, J., Wang, R. H. J., Hartley, D. E., Harth, C., Steele, L. P., Sturrock, G., Midgley, P. M., and McCulloch, A.: A history of chemically and radiatively important gases in air deduced from ALE/GAGE/AGAGE, J. Geophys. Res., 105, 1775117792, doi:10.1029/2000JD900141, 2000.

Rigby, M., Manning, A. J., and Prinn, R. G.: Inversion of long-lived trace gas emissions using combined Eulerian and Lagrangian chemical transport models, Atmos. Chem. Phys., 11, 9887-9898, doi:10.5194/acp-11-9887-2011, 2011.

Rigby, M., Manning, A. J., and Prinn, R. G.: The value of highfrequency, high-precision methane isotopologue measurements for source and sink estimation, J. Geophys. Res., 117, D12312, doi:10.1029/2011JD017384, 2012.

Ryall, D. B. and Maryon, R. H.: Validation of the UK Met. Office's name model against the ETEX dataset, Atmos. Environ., 32, 4265-4276, doi:10.1016/S1352-2310(98)00177-0, 1998.

Saikawa, E., Schlosser, C. A., and Prinn, R. G.: Global modeling of soil nitrous oxide emissions from natural processes, Global Biogeochem. Cy., 27, 972-989, doi:10.1002/gbc.20087, 2013.
Skiba, U., Jones, S. K., Dragosits, U., Drewer, J., Fowler, D., Rees, R. M., Pappa, V. A., Cardenas, L., Chadwick, D., Yamulki, S., and Manning, A. J.: UK emissions of the greenhouse gas nitrous oxide., Philos. T. Roy. Soc. B, 367, 1175-1185, doi:10.1098/rstb.2011.0356, 2012.

Stein, M. L., Interpolation of spatial data: some theory for kriging, Springer, New York, NY, USA, 1999.

Thompson, R. L., Gerbig, C., and Rödenbeck, C.: A Bayesian inversion estimate of $\mathrm{N}_{2} \mathrm{O}$ emissions for western and central Europe and the assessment of aggregation errors, Atmos. Chem. Phys., 11, 3443-3458, doi:10.5194/acp-11-3443-2011, 2011.

Thompson, R. L., Ishijima, K., Saikawa, E., Corazza, M., Karstens, U., Patra, P. K., Bergamaschi, P., Chevallier, F., Dlugokencky, E., Prinn, R. G., Weiss, R. F., O’Doherty, S., Fraser, P. J., Steele, L. P., Krummel, P. B., Vermeulen, A., Tohjima, Y., Jordan, A., Haszpra, L., Steinbacher, M., Van der Laan, S., Aalto, T., Meinhardt, F., Popa, M. E., Moncrieff, J., and Bousquet, P.: TransCom $\mathrm{N}_{2} \mathrm{O}$ model inter-comparison - Part 2: Atmospheric inversion estimates of $\mathrm{N}_{2} \mathrm{O}$ emissions, Atmos. Chem. Phys., 14, 6177-6194, doi:10.5194/acp-14-6177-2014, 2014.

Van der Werf, G. R., Randerson, J. T., Giglio, L., Collatz, G. J., Mu, M., Kasibhatla, P. S., Morton, D. C., DeFries, R. S., Jin, Y., and van Leeuwen, T. T.: Global fire emissions and the contribution of deforestation, savanna, forest, agricultural, and peat fires (1997-2009), Atmos. Chem. Phys., 10, 11707-11735, doi:10.5194/acp-10-11707-2010, 2010.

Yadav, V. and Michalak, A. M.: Improving computational efficiency in large linear inverse problems: an example from carbon dioxide flux estimation, Geosci. Model Dev., 6, 583-590, doi:10.5194/gmd-6-583-2013, 2013. 